\title{
TRENDS IN LIFETIME CANNABIS USE AMONG CZECH SCHOOL-AGED CHILDREN FROM 2002 TO 2014
}

\author{
Ladislav Kážmér ${ }^{1,2}$, Ladislav Csémy ${ }^{1}$, Ingrid Ružbarskáa ${ }^{3}$ Jan Pavelka ${ }^{4}$, Zdeněk Hamřík ${ }^{5}$, Michal Kalman ${ }^{4}$ \\ ${ }^{1}$ Centre of Epidemiological and Clinical Research of Drug Abuse and Dependence, National Institute of Mental Health, Klecany, Czech Republic \\ ${ }^{2}$ Department of Social Geography and Regional Development, Faculty of Sciences, Charles University, Prague, Czech Republic \\ ${ }^{3}$ Faculty of Education, University of Presov in Presov, Presov, Slovakia \\ ${ }^{4}$ Institute of Active Lifestyle, Faculty of Physical Culture, Palacký University Olomouc, Olomouc, Czech Republic \\ ${ }^{5}$ Department of Recreation and Leisure Studies, Faculty of Physical Culture, Palacký University Olomouc, Olomouc, Czech Republic
}

\section{SUMMARY}

Objective: The aim of the study was to examine trends in the prevalence of lifetime cannabis use among the Czech 15-year old students.

Methods: Data from the nationally representative Health Behaviour in School-aged Children Survey, conducted in the Czech Republic in 2002, 2006, 2010 and 2014, were used. Trends in cannabis use among both boys and girls were modelled through binary logistic regression with period as a predictor of the lifetime cannabis use.

Results: The prevalence of lifetime cannabis use has significantly decreased among young Czechs, particularly among boys. Gender differences in cannabis use have been also gradually decreasing since 2002, with no significant differences between genders in recent period.

Conclusions: Although there are positive changes in the prevalence of adolescent cannabis use, from the European perspective, Czech students still belong to those with significantly higher rates in this respect. Thus, alongside with the use of other substances, adolescent cannabis consumption remains an important challenge for the national public health policy.

Key words: cannabis, adolescents, prevalence, trends

Address for correspondence: L. Csémy, National Institute of Mental Health, Topolová 748, 25067 Klecany, Czech Republic. E-mail: csemy@nudz.cz https://doi.org/10.21101/cejph.a5096

\section{INTRODUCTION}

Substance use during adolescence is a serious public health concern $(1,2)$ with significant impact on society as a whole. Among illicit substances, cannabis is the most prevalent psychoactive drug with consumption primarily concentrated among young population (3). From an international perspective, the Czech Republic belongs to countries with relatively high rates of illicit substance use (4), which is apparent particularly for cannabis use. For example, data from the recent European Drug Report indicate that, in 2015 , almost one in five $(18.8 \%)$ young adults aged 15-34 years had used cannabis in the past year, ranking the Czech Republic on 3rd position among European countries $(4,5)$.

In epidemiology, there is a rich scientific evidence documenting how early and intensive cannabis use can lead to a number of physical, mental and social problems during the adolescence or later in adulthood (6). Although there is still a debate on its causal link to other substances $(7,8)$, cannabis is frequently regarded as a getaway to other forms of illicit drug use $(9,10)$. This increased risk of later drug-related problems is of particular concern among individuals where the first experience with drug occurs before mid-adolescence $(11,12)$.

Given the specific vulnerability of juveniles to substance use related consequences, research on adolescent illicit drug use provides an important insight into the complex picture of both adolescent health assessment and national drug monitoring. Applying internationally comparable data, we analyse both the prevalence of cannabis use among the Czech 15-year old youths and possible temporal changes in this respect. As the prevalence rates of substance use typically vary between boys and girls, gender specific differences are also taken account.

\section{MATERIAL AND METHODS}

The data used in our analysis were obtained through the Health Behaviour in School-aged Children study (HBSC). The aim of HBSC is to increase understanding of adolescent health behaviours as well as general health and wellbeing in the specific social context of adolescents. This is achieved through the collection of high quality data available for both scientific and policy purposes, obtained by large cross-national school-based research (13). In the Czech Republic, HBSC has been conducted every four years since 1994 and it provides reliable and comparable database for variety of adolescent health indicators.

As regards adolescents' substance use, HBSC provides data on consumption of both licit (tobacco, alcohol) and illicit substances (cannabis). Data on adolescent cannabis use are available 
since 2002, providing information on the prevalence of lifetime cannabis use during the last 12-year period (2002-2014). The HBSC provides some additional data on cannabis use (past year prevalence, past month prevalence), however, these data were not collected regularly; thus, they were not suitable for our analysis.

In HBSC, the question on lifetime cannabis use was surveyed amongst 15-year-old respondents only (i.e. younger student cohorts were not included in this part of the questionnaire). Students reported the frequency of cannabis use in their life on a 7-point scale ranging from "never" to "40 times or more". Those who reported at least one cannabis experience in their life were classified as lifetime cannabis users. The data were collected during the survey using an anonymous self-reported questionnaire, where all respondents participated on voluntary basis. Therefore, no consent was required for the study.

The statistical analysis was conducted in two steps. First, prevalence estimates of lifetime cannabis use with corresponding $95 \%$ confidence intervals $(95 \% \mathrm{CI})$ were computed for both genders and plotted to graph. Gender differences in prevalence estimates were tested by both Pearson Chi-square statistic and Mantel-Haenszel common odds ratio (14). Second, trends in lifetime cannabis use were modelled by binary logistic regression. In the model, survey period was used as a predictor of the lifetime cannabis use.

\section{RESULTS}

As already stated above, we used data from the last four HBSC studies conducted in the Czech Republic from 2002 to 2014. Table 1 summarizes sample sizes of 15 -year-old students

Table 1. Sample structure for the study by gender and the year of survey, 15 years old students, Czech Republic, HBSC data 2002-2014 $(N=6,607)$

\begin{tabular}{|l|c|c|c|c|}
\hline \multirow{2}{*}{} & \multicolumn{4}{|c|}{ Year of survey } \\
\cline { 2 - 5 } & $\mathbf{2 0 0 2}$ & $\mathbf{2 0 0 6}$ & $\mathbf{2 0 1 0}$ & $\mathbf{2 0 1 4}$ \\
\hline Boys & 806 & 842 & 747 & 852 \\
\hline Girls & 854 & 823 & 775 & 908 \\
\hline Total & 1,660 & 1,665 & 1,522 & 1,760 \\
\hline
\end{tabular}

surveyed in each cross-sectional period. The size of samples varied from 1,522 in 2010 to 1,760 in 2014, with a proportional share of both genders. In the analysis, a total sample of 6,607 respondents compiled from four surveys was used (3,247 boys and 3,360 girls). With regards to the response rates, the share of missing responses on lifetime cannabis use did not exceed $4 \%$ in any survey. The overall percentage of missing values in the compiled dataset was also very low $(2.7 \%)$.

Table 2 presents time series of the estimated share of 15 -yearsold Czechs, who have ever used cannabis in their life. Both separate estimates by gender and total prevalence rates are presented. The total prevalence rate varied from $30.5 \%$ in 2002 to $23.1 \%$ in 2014. Additionally, gender differences were tested by Pearson Chi-square and Mantel-Haenszel common odds ratio statistics. While in 2002 there were clear gender differences in lifetime cannabis use with significantly lower rate among girls $(\mathrm{OR}=0.69$, $\mathrm{p}<0.001$ ), these differences gradually decreased in later periods. In 2010 and 2014, no significant differences were detected.

The following Fig. 1 summarizes trends in lifetime cannabis use separately for boys and girls; $95 \%$ CIs are also plotted. There is a gradual decline in the proportion of students with the lifetime cannabis experience, particularly among boys. Among girls, the time series has a rather fluctuating character with no clear temporal trend. This resulted in a gradual de-

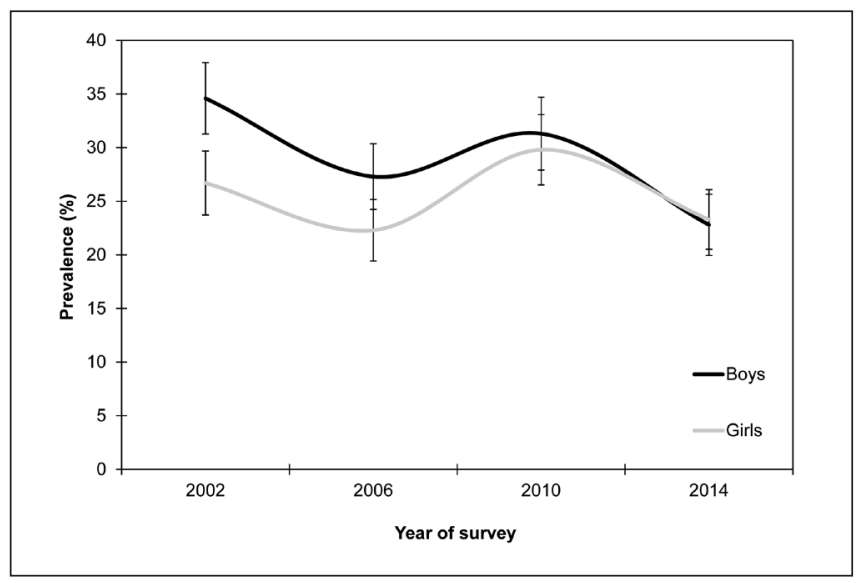

Fig. 1. Trends in lifetime cannabis use in 15 years old students by gender (\%, 95\% Cl), Czech Republic, HBSC (2002-2014).

Table 2. Prevalence estimates of lifetime cannabis use in 15 years old students by gender and the year of survey, Czech Republic, HBSC (2002-2014)

\begin{tabular}{|c|c|c|c|c|}
\hline & \multicolumn{4}{|c|}{ Year of survey } \\
\hline & 2002 & 2006 & 2010 & 2014 \\
\hline \multicolumn{5}{|l|}{ Prevalence estimates (\%) } \\
\hline Boys & 34.6 & 27.3 & 31.3 & 22.8 \\
\hline Girls & 26.7 & 22.3 & 29.8 & 23.3 \\
\hline Total & 30.5 & 24.8 & 30.5 & 23.1 \\
\hline \multicolumn{5}{|c|}{ Tests of gender differences } \\
\hline Pearson chi-square (df) & $12.25(1)$ & $5.35(1)$ & $0.37(1)$ & $0.07(1)$ \\
\hline $\mathrm{M}-\mathrm{H}$ odds ratio & 0.69 & 0.77 & 0.93 & 1.03 \\
\hline$p$ value & $<0.001$ & 0.021 & 0.544 & 0.791 \\
\hline
\end{tabular}

$\mathrm{p}$ values are 2-sided; $\mathrm{M}-\mathrm{H}-$ Mantel-Haenszel common odds ratio (girls vs. boys). 
Table 3. Binary logistic regression by gender. Dependent variable - Lifetime cannabis use in 15 years old students, Czech Republic, HBSC (2002-2014)

\begin{tabular}{|l|l|c|c|c|}
\hline \multicolumn{2}{|l|}{} & Beta (SE) & p value & Exp(Beta) $(95 \%$ CI) \\
\hline \multirow{3}{*}{ Boys } & Time perioda) & $-0.04(0.009)$ & $<0.001$ & $0.96(0.945-0.978)$ \\
\cline { 2 - 5 } & Constant & $-0.67(0.064)$ & $<0.001$ & $0.51(0.451-0.578)$ \\
\hline \multirow{3}{*}{ Girls } & Time perioda) & $0.00(0.009)$ & 0.601 & $1.00(0.978-1.013)$ \\
\cline { 2 - 5 } & Constant & $-1.05(0.066)$ & $<0.001$ & $0.35(0.308-0.399)$ \\
\hline \multirow{2}{*}{ Total } & Time perioda) & $-0.02(0.006)$ & $<0.001$ & $0.98(0.966-0.990)$ \\
\cline { 2 - 5 } & Constant & $-0.86(0.046)$ & $<0.001$ & $0.42(0.387-0.463)$ \\
\hline
\end{tabular}

a) Continuous variable, number of years since the baseline period 2002. Lifetime cannabis use: Yes $=1$, No $=0$

crease of differences in the prevalence of lifetime cannabis use between the genders.

In the last step, temporal trends were tested through the binary logistic regression. In the model, survey period was used as an independent predictor of the lifetime cannabis use. It was measured as a continuous variable indicating the number of years since the baseline period 2002 (i.e. "0" for 2002; “4” for 2006, etc.). The analysis was conducted both separately for genders and for total prevalence. Results are presented in Table 3.

The regression analysis confirmed previous results summarised in Table 2 and Fig. 1. The total prevalence of lifetime cannabis use significantly decreased from 2002 to 2014 (Beta $=-0.02$; $\mathrm{p}<0.001)$. However, temporal trends were different between genders (Z-test for difference in Beta coefficients between boys and girls $=-3.14, p=0.002$ ). While the gradual decline in the prevalence of lifetime cannabis use was pronounced particularly among boys ( Beta $\left._{\text {Boys }}=-0.04 ; \mathrm{p}<0.001\right)$, there was no significant change in the prevalence among girls $\left(\right.$ Beta $\left._{\text {Girls }}=0.00 ; \mathrm{p}=0.601\right)$.

\section{DISCUSSION}

Results of the analysis clearly pointed to a downward trend in the prevalence of cannabis use among the Czech youth. Although we had to limit the study only to the examination of lifetime cannabis use, our results can be compared with some other studies focused on the level of adolescent cannabis consumption.

The issue of decreasing trends in cannabis use among the school-age youngsters, particularly among those living in western societies, has been already presented by some authors. Kuntsche et al. (2) studied the prevalence of adolescent past year cannabis use, and found that in most of the 31 countries there was a decrease in the prevalence from 2002 to 2006 . In a similar manner, Brooks-Russell et al. (15) found that from 1998 to 2010, there was a continuous decline in the past year cannabis use among the 10th grade students living in the United States. The study by Hublet et al. (16) generally confirmed the decreasing trend in adolescent cannabis use both in Europe and North America - despite some regional variations particularly among Eastern European countries. According to latest data published by the 2015 European School Survey Project on Alcohol and Other Drugs (ESPAD) report (17), the prevalence of lifetime cannabis use among the Czech 16-year old students also continually declined from 2003 to 2015. Put together, all these positive trends are in congruence with our analysis and point to lowering prevalence of adolescent cannabis use as a rather more general trend in developed countries.
Nevertheless, as documented by recent international studies surveyed by both HBSC (2014) and ESPAD (2015) consortiums, the Czech adolescents still belong to those with a relatively extensive cannabis use as compared to their counterparts from other European countries. For example, in 2015, the rate of adolescent lifetime cannabis use in the Czech Republic was 2.3times higher than the ESPAD average (17). Similar results were published for 2014 by the HBSC report (the Czech rate was 1.5times higher than the average from all HBSC countries) (18). For current cannabis use, defined as the prevalence of use within the last 30 days, the Czech rate was twice as high as the 2015 ESPAD average (17). Furthermore, the age of cannabis initiation among the Czech students was also relatively low (in 2014, the percentage of 15 -year-olds, who used cannabis at the age 13 or earlier, was 2.2 times higher among Czechs than in other HBSC countries) (18). Therefore, the issue of adolescent cannabis consumption, as well as the use of other substances, cannot be neglected. This is particularly important due to the fact that in the Czech Republic the availability of cannabis is still relatively high and possession of low amount of marijuana is not defined as a criminal act any more (19).

There can be several factors underlying recent positive trends in cannabis use among the Czech youth. In this regard we emphasize, however, social factors, especially those responsible for changes in patterns of leisure time activities of the contemporary youth. In the study of Kuntsche et al. (2) authors demonstrated that in most countries participating in the HBSC project, the decrease in adolescent cannabis use from 2002 to 2006 occurred in accordance with general decrease in frequency of going out with their friends. Results from the recent research presented by Chomynová et al. (20) provides empirical evidence on significant changes in leisure time activities among the Czech adolescents as well. Applying the Czech data obtained within six waves of the ESPAD study (1995-2015), they document that since 2003 there has been strong and gradual decline in the proportion of students going out with their friends, seeking for various fun activities (e.g. parties, discos, etc.). On the other hand, proportion of students preferring internet surfing as a leisure time activity and using various tools of information and communication technologies for entertainment strongly increased. Thus, adolescents nowadays seem to spend significantly less time with their peers than the Czech youth twelve years ago. Additionally, changes in higher awareness and/or perceptions of risks associated with the cannabis use do not seem to explain the positive trend (there are no significant changes from 2003 to 2015 as documented by Chomynová et al.) (20). Therefore, in accordance with the 
international research conducted by Kuntsche et al. (2) and their reference to the concept of "exposure opportunity" (21), it seems to be plausible that new modes of leisure time activities mostly contribute to the lowering prevalence of (lifetime) cannabis use. This can be attributed to the contemporary Czech youths, as well as to adolescents living in other countries in general.

At the end of the discussion, we also point to some methodical considerations related to our study. In the analysis, representative data from large sample school-based research with internationally unified methodology were used. This is undoubtedly a strength of the study. However, we should also mention that the data rely on self-reported responses of students present in the school at the time of survey. This could partially underestimate prevalence rates of illicit substance use due to both willingness to disclose accurate information on socially undesirable behaviour and possibly higher rates of school absenteeism among adolescent substance users. Although there can be several factors related to reliability of the data, the available research evidence suggest that self-reports on adolescent substance use are mostly valid and reliable. This applies especially to studies where surveys are anonymous and confidentiality of responses is assured $(22,23)$, as in our research.

\section{CONCLUSIONS}

The study provides an empirical evidence on decreasing trend in the prevalence of adolescent cannabis use in the Czech Republic. This positive development is consistent with some other studies focusing on adolescent cannabis consumption, conducted in developed countries. The analysis showed that the decreasing trend was present particularly among boys. This resulted in shrinking gender differences in the prevalence of lifetime cannabis use among the Czech youths. Although the lowering prevalence is seen to be a positive trend, it has to be emphasized that adolescents in the Czech Republic still belong to those with relatively high rates of cannabis consumption comparing to other European teenagers.

\section{Acknowledgements}

The study was supported by the project "Sustainability" for the National Institute of Mental Health (grant number LO1611) with a financial support from the Ministry of Education, Youth and Sports of the Czech Republic under the NPU I program.

\section{Conflict of Interests}

None declared

\section{REFERENCES}

1. Bauman A, Phongsavan P. Epidemiology of substance use in adolescence: prevalence, trends and policy implications. Drug Alcohol Depend. 1999 Jul 1;55(3):187-207.

2. Kuntsche E, Simons-Morton R, Fotiou A, ter Bogt T, Kokkevi A; Health Behavior in School-Aged Children Study. Decrease in adolescent cannabis use from 2002 to 2006 and links to evenings spent out with friends in 31 European and North America countries and regions. Arch Pediatr Adolesc Med. 2009 Feb;163(2):119-25.
3. United Nations Office on Drugs and Crime (UNODC). World drug report 2015. Vienna: United Nations publications; 2015.

4. European Monitoring Centre for Drugs and Drug Addiction. Czech Republic, Country drug report 2017. Luxembourg: Publications Office of the European Union; 2017.

5. Mravčík V, Chomynová P, Grohmannová K, Janíková B, Tion Leštinová Z, Rous Z, et al. Annual report on drug situation 2015 - Czech Republic. Prague: Office of the Government of the Czech Republic; 2016. (In Czech.)

6. Volkow ND, Baler RD, Compton WM, Weiss SR. Adverse health effects on marijuana use. N Engl J Med. 2014 Jun 5;370(23):2219-27.

7. Morral AR, McCaffrey DF, Paddock SM. Reassessing the marijuana gateway effect. Addiction. 2002 Dec;97(12):1493-504.

8. Moss HB, Chen CM, Yi HY. Early adolescent patterns of alcohol, cigarettes, and marijuana polysubstance use and young adult substance use outcomes in a nationally representative sample. Drug Alcohol Depend. 2014 Mar 1;136:51-62.

9. Kandel D. Stages in adolescent involvement in drug use. Science. 1975 Nov 28;190(4217):912-4.

10. Lynskey MT, Vink JM, Boomsma DI. Early onset cannabis use and progression to other drug use in a sample of Dutch twins. Behav Genet. 2006 Mar;36(2):195-200.

11. Anthony JC, Petronis KR. Early-onset drug use and risk of later drug problems. Drug Alcohol Depend. 1995 Nov;40(1):9-15.

12. Griffin KW, Bang H, Botvin GJ. Age of alcohol and marijuana use onset predicts weekly substance use and related psychosocial problems during young adulthood. J Subst Use. 2010;15(3):174-83.

13. Roberts C, Currie C, Samdal O, Currie D, Smith R, Maes L. Measuring the health and health behaviours of adolescents through cross-national survey research: recent developments in the Health Behaviour in Schoolaged Children (HBSC) study. J Public Health. 2007 Jun;15(3):179-186.

14. Agresti A. An introduction to categorical data analysis. 2nd ed. Hoboken (NJ): John Wiley and Sons; 2007.

15. Brooks-Russell A, Farhat T, Haynie D, Simons-Morton B. Trends in substance use among 6th- to 10th-grade students from 1998 to 2010: findings from a national probability study. J Early Adolesc. 2014 Jun;34(5):667-80.

16. Hublet A, Bendtsen P, de Looze ME, Fotiou A, Donnelly P, Vilhjalmsson $\mathrm{R}$, et al. Trends in the co-occurrence of tobacco and cannabis use in 15-year-olds from 2002 to 2010 in 28 countries of Europe and NorthAmerica. Eur J Public Health. 2015 Apr;25 Suppl 2:73-5.

17. Kraus L, Guttormsson U, Leifman H, Arpa S, Molinaro S, Monshouwer K, et al. ESPAD Report 2015. Results from the European School Survey Project on Alcohol and Other Drugs. Luxembourg: Publications Office of the European Union; 2016.

18. Inchley J, Currie D, Young T, Samdal O, Torsheim T, Augustson L, et al., editors. Growing up unequal: gender and socioeconomic differences in young people's health and well-being. Health Behaviour in School-aged Children (HBSC) study: international report from the 2013/2014 survey. Copenhagen: WHO Regional Office for Europe; 2016.

19. Csémy L, Sovinová H, Procházka B. Alcohol consumption and marijuana use in young adult Czechs. Cent Eur J Public Health. 2012 Dec;20(4):2447.

20. Chomynová P, Csémy L, Mravčík V. European School Project on Alcohol and other Drugs (ESPAD) 2015. Zaostřeno. 2016;2(5):1-16. (In Czech.)

21. Van Etten ML, Neumark YD, Anthony JC. Initial opportunity to use marijuana and the transition to first use: United States, 1979-1994. Drug Alcohol Depend. 1997 Dec;49(1):1-7.

22. Murray DM, Perry CL. The measurement of substance use among adolescents: When is the 'bogus pipeline' method needed? Addict Behav. 1987;12(3):225-33.

23. Aguinis H, Peirce CA, Quigley BM. Enhancing the validity of self-reported alcohol and marijuana consumption using a bogus pipeline procedure: a meta-analytic review. Basic Appl Soc Psych. 1995 Jun;16(4):515-27. 